Biologia Futura

https://akademiai.com/loi/019

\title{
The future of biology from a canine perspective
}

\author{
Péter Pongrácz \\ Department of Ethology, Eötvös Loránd University, Budapest, Hungary
}

DOI: $10.1556 / 019.70 .2019 .11$

\section{Editorial Foreword}

Cite this article: Pongrácz P. 2019.

The future of biology from a canine perspective. Biol. Fut. 70, 89-92.

The present issue of Biologia Futura is dedicated to a selected array of theoretical and empirical studies that were originally presented at the 6th Canine Science Forum in 2018, Budapest, Hungary. Some of our readers might ask the question: "What is so special in dogs (and related canids) that gives justification for such distinct attention?" This question is rather easy to answer from the scientific point of view when we consider the exponential growth of the number of researchers, research groups, and consequently the amount of conferences and publications that are involved in the investigation of the biology of canid species, predominantly dogs. Although the "renaissance" of canine research mainly arose from the field of behavioral biology in the 1990s (Topál et al., 2009b), it is rather obvious that apart from ethologists, many subdisciplines of zoology became involved in the research of wild and domesticated canids more recently. Driven by this realization, in 2008, we launched the Canine Science Forum, a biannual international effort of likeminded researchers, to provide a framework that helps focus and simultaneously diversify these research efforts. In the past 30 years, the international community of scientists involved in the investigation of canid biology have published hundreds of highly influential papers, ranging from molecular genetics (e.g., Wayne \& Ostrander, 2007) to behavioral ecology (e.g., Bonanni et al., 2010), evolutionary biology (e.g., Wang et al., 2013), welfare science (e.g., Hiby et al., 2004), neuroethology (e.g., Andics et al., 2016), and comparative cognition (e.g., Topál et al., 2009a).

However, we owe another answer to the readers: why did we compile a special issue for Biologia Futura solely from canine-related papers? The reason is just as simple as it is beautiful - this current selection of research articles provides excellent evidence that, independent of the model organism, it is possible to do "good science" if researchers pursue the goal of venturing toward untrodden pathways, no matter which field of biology they are coming from. The selection of papers the reader finds in this issue testifies that the future of biology is just as exciting as the past, both are filled with the thrill of discovery.

\section{THEORIES, MODELS, AND THEIR REALITY - CANINE SCIENCE FEATURING TINBERGEN'S FOUR QUESTIONS}

Ethology is unique from several aspects - for example, it predominantly concentrates on phenomena at the level of individuals (unlike the numerous infra- and supraindividual subdisciplines in biology) and also because ethologists often have to decide which organizational aspect of behavior will they investigate. The traditional fourfold division of research (either directed at the function, evolution, mechanism, and ontogeny of the behavior) suggested by Tinbergen (Bateson \& Laland, 2013) can be clearly applied to the otherwise vastly various topics of canid-related research as well.

\author{
Author for correspondence: \\ Péter Pongrácz \\ e-mail: peter.pongracz@ttk.elte.hu
}

(C) 2019 The Author(s)

\section{EVOLUTION}

When it comes to evolution, the origin of the domesticated dog (Canis familiaris) appears to be the most obvious and commonly investigated field. Besides the long line of molecular genetics (e.g., Pollinger et al., 2010) and archeological discoveries

This is an open-access article distributed under the terms of the Creative Commons Attribution 4.0 International License, which permits unrestricted use, distribution, and reproduction in any medium, provided the original author and source are credited, a link to the CC License is provided, and changes - if any - are indicated. (SID_1) 
(Larson et al., 2012), a vivid theoretical debate arose with regard to the timing (e.g., MacHugh et al., 2017), location (e.g., Savolainen et al., 2002), and mechanism (Trut et al., 2004) of dog domestication. Although researchers do not always agree on who played the main role in this process (human-driven vs. self-domestication hypotheses; see Driscoll et al., 2009), the hypothetical "first step" of domestication was firmly believed to be some sort of selection for a new, advantageous phenotype.

At present, Biologia Futura offers the chance to read about a provocative new theory, called "active social domestication" (Pörtl \& Jung, 2019), wherein, the social environment induced neurophysiological changes in the foundation stock of hypothetical dog ancestors, which would cause an epigenetic cascade effect that led to a relatively rapid unfolding of the so-called domestication syndrome (Meaney \& Szyf, 2005; Trut et al., 2009). As with any markedly new theory, heated scientific discussions will likely follow, we also have to add that "active social domestication" provides an option for a new genre of empirical tests to unfold.

\section{INTRASPECIFIC SOCIAL BEHAVIOR AND A TOUCH OF ONTOGENY}

Social behavior has central importance for both the cognitive and evolutionary aspects of canine science. The sociocognitive competence of dogs has provided an excellent model for comparative ethologists to formulate theories about the evolution of analogous mental capacities in dogs and humans (Miklósi \& Topál, 2013), and there is fertile theoretical debate about the main social/behavioral features that hallmarked the separation of dogs from their closest extant relative, the gray wolf (see Hare et al., 2010; Udell et al., 2010). Future research directions are either expected to involve well-designed, controlled field experiments of the various dog-dog and dog-human interactions (Pongrácz et al., 2014) or contrarily enter the depths of understanding through the neural mechanisms beyond specific sociocognitive capacities of the canids (e.g., Andics et al., 2014). The study of Iotchev et al. (2019) fits to the "new age" of canine science as they were interested in the demographic factors (age, sex, and reproductive status) that could influence the dyadic interactions of companion dogs that were unfamiliar with each other in a naturalistic environment (a dog park). Based on the results of Iotchev et al. (2019), it is clear that unfamiliar companion dogs spend only a relatively small proportion of their free-ranging time interacting with each other. Females initiated dyadic interactions sooner and remained with their canine partner longer than males. Male dogs on the other hand spent more time following other dogs. The frequency and intensity of dyadic interactions decreased with the age of dogs. Unlike the previous study, Lenkei et al. (2019) were interested in the early development of social behavior of companion dogs, and they chose a rather infrequently used method to study their subjects they visited hobby breeders in their homes. By testing several litters of 8-week-old Labrador Retrievers and Czechoslovakian Wolf Dogs, they found that, independent of the breed, the early separation of the puppies from their mother had an effect on the subjects' reaction to novel environment and unfamiliar humans. Puppies that had been kept separately from their mother spent more time gazing at the unfamiliar experimenter when they were exposed to noise - probably showing that being raised at least partially separated from the mother, may increase insecure behaviors in young dogs.

\section{FUNCTIONALLY VITAL - SOCIAL COGNITION ON THE INTERSPECIFIC LEVEL}

Dog-human interactions serve as a popular model for investigating fundamental questions of comparative social cognition (Topál et al., 2009b). Kiss and Topál (2019) focused on the so-called "audience effect," in which humans serve as a basic building block for many complex sociocognitive abilities, including the following of rules. Audience effect is the influence wherein the mere presence, or more specifically, the apparent attention of others ("gazing") that affects the actions of the subject while he/she is engaged in a specific action. Traditionally, this phenomenon is tested on dogs in circumstances where the action would be otherwise forbidden to the dog (e.g., stealing a piece of food in the presence of the owner; Kaminski et al., 2013). The results of the Kiss and Topál's (2019) study showed that dogs can be sorted into three categories ("always obedient," "always ignorant," and "hesitating") with regard to their reactions in the forbidden food task. By analyzing the gazing directions of the subjects, the authors found that "always obedient" dogs keep gazing at the human partner instead of the food, "always ignorant" dogs do not gaze at the human, and "hesitant" dogs tend to look at the food before they would steal it, but after the deed they gaze rather to that person who might see their action. These findings about the role of individual differences among dogs regarding the effect of a human "audience" on their forbidden activity fits well to the steadily growing interest in animal personalities and individual strategies (e.g., Rudin et al., 2019).

One of the basic requirements for sophisticated social interactions is the capacity of individual recognition. Although this is a widespread phenomenon among conspecifics (Tibbetts \& Dale, 2007), interspecific individual recognition is much less frequently documented (Proops $\&$ McComb, 2012). Selective processes may only favor the emergence of this capacity when the (mutual) interdependence and level of interactions between two species reach a particular threshold - which has undoubtedly happened in the case of dogs and humans. It is widely accepted that dogs evolved to be potentially highly dependent on humans, including a strong, lifelong attachment bond between dogs and their owners; therefore, at first look, the experiment of Gábor et al. (2019) would seem a triviality: do dogs recognize their owners based on acoustic cues only? However, as a similar experiment that involved finding the owner by following its scent among real-life conditions recently showed a surprising failure of dogs (Polgár et al., 2015), the outcome of the present paper was also not easy to 
predict. Contrary to the olfactory cues, the owner's voice was a salient enough stimulus for the dogs to find their hidden master and discriminate his/her location from a similarly talking stranger's location (Gábor et al., 2019). This result, compared to the study with the one where companion dogs were not ready to use olfactory cues (which otherwise they obviously can learn to follow - e.g., the widespread use of tracking dogs) when they had to find their hidden owner, raises the intriguing hypothesis whether dogs shifted their everyday communicative strategy toward acoustic communication both as signalers (Pongrácz, 2017) and receivers, when it comes to interaction with humans.

\section{FUTURE APPLICATIONS OF CANINE SCIENCE}

One of the most dynamically developing research directions in behavioral sciences is applied ethology. Due to the fact that dogs coexist with people in vast numbers all around the world, and dog-human interactions without doubt, represents the most complex interspecific relationship, canine science is in the vanguard of applied research as well. From the results of Shorter and Brown (2019), it is clear that applied behavioral research should be included to the development and deployment of even the most triviallooking equipment that will be used in connection with our domesticated companions. They investigated whether dog boots (which are becoming more popular for use by both companion and working dogs) affect the ground force kinetics of dogs wearing them during locomotion. By employing specific measuring techniques, their results showed that at least one crucial kinetic parameter (peak vertical instantaneous loading rate) was higher in shod dogs than in the barefoot controls.

The ubiquity of dogs as popular companions comes with serious animal welfare costs as it shows in the vast number of abandoned, lost, and unwanted dogs waiting for adoption at dog shelters worldwide. Meanwhile, preventive work would be of primary importance (i.e., how to lower the number of relinquished dogs) and the pre- and post-adoption assessment of dog behavior is also a key aspect of the safe and successful re-homing of dogs. The new aspect in the paper of Reem (2019) was that the author compared the post-adoption behavior of two types of dogs: those that came from a shelter and those that were transferred to the adopters directly from their previous owners. Through phone interviews with the new owners, the author surveyed the occurrence of typical behavioral problems and concluded that with the exception of house training (i.e., inappropriate elimination), there was no significant difference between the two groups' behavior. This result can strengthen the position of dog shelters as a suitable source for dog adoption. Still, one should bear in mind that apart from the behavioral problems that may occur in dogs that came from a shelter (Winslow et al., 2018), the shelter environment usually causes serious stress to its inhabitants (Gunter et al., 2019); therefore, re-homing of dogs from owner to owner is probably the better solution.
Beyond new theoretical approaches, methodological inventions are among those key elements that symbolize best the mission of Biologia Futura, as these will most likely serve researchers in a larger number of studies in the future. O'Hara and Worsley (2019) sought the answer of a long-time existing problem in cognitive neuroethology: "brain or behavior"? This means that currently there are no such neuroimaging techniques that could provide data about brain activity while the subject is moving. In their study, they tested a thermoscanner, which is a cheap, non-invasive, and easy-to-use tool that provides data by measuring the subjects' temperature within the ear. O'Hara and Worsley (2019) could detect increased temperature in the right ear of the dogs when the subjects were exposed to mild stress (frustration due to the omission of expected treats) - which is likely to be the consequence of the activation of the stress-processing cortical brain regions in the right hemisphere. Finally, we would like to draw the reader's attention to the work of Czeibert et al. (2019), who created an up-to-date detailed canine brain label map. As the dog becomes a more commonly used subject of various neuroimaging techniques (Andics et al., 2016), the research groups would greatly benefit from a standardized and freely available template. The template and label map described by Czeibert et al. (2019) in Biologia Futura will hopefully promote comparability of anatomical works between laboratories. Our goal, parallel with the goal of the authors, cannot be less than support a greater number of upcoming, non-invasive investigations of social and cognitive neuroscience.

\section{REFERENCES}

Andics, A., Gábor, A., Gácsi, M., Faragó, T., Szabó, D., Miklósi, A. (2016) Neural mechanisms for lexical processing in dogs. Science 353(6303), 1030-1032.

Andics, A., Gácsi, M., Faragó, T., Kis, A., Miklósi, Á. (2014) Voice-sensitive regions in the dog and human brain are revealed by comparative fMRI. Curr. Biol. 24(5), 574-578.

Bateson, P., Laland, K. N. (2013) Tinbergen's four questions: an appreciation and an update. Trends Ecol. Evol. 28(12), 712-718.

Bonanni, R., Valsecchi, P., Natoli, E. (2010) Pattern of individual participation and cheating in conflicts between groups of freeranging dogs. Anim. Behav. 79(4), 957-968.

Czeibert, K., Andics, A., Petneházy, Ö., Kubinyi, E. (2019) A detailed canine brain label map for neuroimaging analysis. Biol. Fut. 70(2), 112-120.

Driscoll, C. A., Macdonald, D. W., O’Brien, S. J. (2009) From wild animals to domestic pets, an evolutionary view of domestication. Proc. Natl. Acad. Sci U. S. A. 106, 9971-9978.

Gábor, A., Kaszás, N., Miklósi, Á., Faragó, T., Andics, A. (2019) Interspecific voice discrimination in dogs. Biol. Fut. 70(2), 121-127.

Gunter, L. M., Feuerbacher, E. N., Gilchrist, R. J., Wynne, C. D. (2019) Evaluating the effects of a temporary fostering program on shelter dog welfare. PeerJ 7, e6620.

Hare, B., Rosati, A., Kaminski, J., Bräuer, J., Call, J., Tomasello, M. (2010) The domestication hypothesis for dogs' skills with human communication: a response to Udell et al. (2008) and Wynne et al. (2008). Anim. Behav. 79(2), e1-e6. 
Hiby, E. F., Rooney, N. J., Bradshaw, J. W. S. (2004) Dog training methods: their use, effectiveness and interaction with behaviour and welfare. Anim. Welf. 13(1), 63-70.

Iotchev, I. B., Egerer, A., Grafe, S., Adorján, A., Kubinyi, E. (2019) Encounters between pairs of unfamiliar dogs in a dog park. Biol. Fut. 70(2), 156-165.

Kaminski, J., Pitsch, A., Tomasello, M. (2013) Dogs steal in the dark. Anim. Cogn. 16(3), 385-394.

Kiss, O., Topál, J. (2019) How do dogs monitor the human's attentional state after challenged by the presence of forbidden food? Biol. Fut. 70(2), 103-111.

Larson, G., Karlsson, E. K., Perri, A., Webster, M. T., Ho, S. Y., Peters, J., Stahl, P. W., Piper, P. J., Lingaas, F., Fredholm, M., Comstock, K. E., Modiano, J. F., Schelling, C., Agoulnik, A. I., Leegwater, P. A., Dobney, K., Vigne, J. D., Vilà, C., Andersson, L., Lindblad-Toh, K. (2012) Rethinking dog domestication by integrating genetics, archeology, and biogeography. Proc. Natl. Acad. Sci. 109(23), 8878-8883.

Lenkei, R., Pogány, Á., Fugazza, C. (2019) Social behaviour in dog puppies: breed differences and the effect of rearing conditions. Biol. Fut. 70(2), 134-142.

MacHugh, D. E., Larson, G., Orlando, L. (2017) Taming the past: ancient DNA and the study of animal domestication. Ann. Rev. Anim. Biosci. 5, 329-351.

Meaney, M. J., Szyf, M. (2005) Maternal care as a model for experience-dependent chromatin plasticity? Trends Neurosci. $28,456-463$.

Miklósi, Á., Topál, J. (2013) What does it take to become 'best friends'? Evolutionary changes in canine social competence. Trends Cogn. Sci. 17, 287-294.

O'Hara, S. J., Worsley, H. K. (2019) A cost-effective, simple measure of emotional response in the brain for use by behavioural biologists. Biol. Fut. 70(2), 143-148.

Polgár, Z., Miklósi, Á., Gácsi, M. (2015) Strategies used by pet dogs for solving olfaction-based problems at various distances. PLoS One 10, e0131610.

Pollinger, J. P., Vonholdt, B. M., Lohmueller, K. E., Han, E., Parker, H. G., Quignon, P., Degenhardt, J. D., Boyko, A. R., Earl, D. A., Auton, A., Reynolds, A., Bryc, K., Brisbin, A., Knowles, J. C., Mosher, D. S., Spady, T. C., Elkahloun, A., Geffen, E., Pilot, M., Jedrzejewski, W., Greco, C., Randi, E., Bannasch, D., Wilton, A., Shearman, J., Musiani, M., Cargill, M., Jones, P. G., Qian, Z., Huang, W., Ding, Z. L., Zhang, Y. P., Bustamante, C. D., Ostrander, E. A., Novembre, J., Wayne, R. K. (2010) Genome-wide SNP and haplotype analyses reveal a rich history underlying dog domestication. Nature 464(7290), 898.

Pongrácz, P. (2017) Modeling evolutionary changes in information transfer: effects of domestication on the vocal communication of dogs (Canis familiaris). Eur. Psychol. 22, 219-232.
Pongrácz, P., Szabó, É., Kis, A., Péter, A., Miklósi, Á. (2014) More than noise? - field investigations of intraspecific acoustic communication in dogs (Canis familiaris). Appl. Anim. Behav. Sci. 159, 62-68.

Pörtl, D., Jung, C. (2019) Physiological pathways to rapid prosocial evolution. Biol. Fut. 70(2) 93-102.

Proops, L., McComb, K. (2012) Cross-modal individual recognition in domestic horses (Equus caballus) extends to familiar humans. Proc. R. Soc. B Biol. Sci. 279(1741), 3131-3138.

Reem, N. (2019) Shelter-housed versus re-homed dogs: adjustment, behavior, and adoption outcomes. Biol. Fut. 70(2), 149-155.

Rudin, F. S., Simmons, L. W., \& Tomkins, J. L. (2019) Social cues affect quantitative genetic variation and covariation in animal personality traits. Evolution 73(3), 540-553.

Savolainen, P., Zhang, Y. P., Luo, J., Lundeberg, J., Leitner, T. (2002) Genetic evidence for an East Asian origin of domestic dogs. Science 298(5598), 1610-1613.

Shorter, K., Brown, W. (2019) Ground force kinetic adaptations associated with canine boots. Biol. Fut. 70(2), 128-133.

Tibbetts, E. A., Dale, J. (2007) Individual recognition: it is good to be different. Trends Ecol. Evol. 22(10), 529-537.

Topál, J., Gergely, Gy., Erd hegyi, Á., Csibra, G., Miklósi, Á. (2009a) Differential sensitivity to human communication in dogs, wolves, and human infants. Science 325, 1269-1272.

Topál, J., Miklósi, Á., Gácsi, M., Dóka, A., Pongrácz, P., Kubinyi, E., Virányi, Zs., Csányi, V. (2009b) The dog as a model for understanding human social behavior. Adv. Study Anim. Behav. $39,71-116$.

Trut, L., Oskina, I., Kharlamova, A. (2009) Animal evolution during domestication: the domesticated fox as a model. BioEssays 31, 349-360.

Trut, L. N., Plyusnina, I. Z., Oskina, I. N. (2004) An experiment on fox domestication and debatable issues of evolution of the dog. Russ. J. Genet. 40(6), 644-655.

Udell, M. A., Dorey, N. R., Wynne, C. D. (2010) What did domestication do to dogs? A new account of dogs' sensitivity to human actions. Biol. Rev. 85(2), 327-345.

Wang, G. D., Zhai, W., Yang, H. C., Fan, R. X., Cao, X., Zhong, L., Wang, L., Liu, F., Wu, H., Cheng, L. G., Poyarkov, A. D., Poyarkov, N. A., Tang, S. S., Zhao, W. M., Gao, Y., Lv, X. M., Irwin, D. M., Savolainen, P., Wu, C. I., Zhang, Y. P. (2013) The genomics of selection in dogs and the parallel evolution between dogs and humans. Nat. Commun. 4, 1860.

Wayne, R. K., Ostrander, E. A. (2007) Lessons learned from the dog genome. Trends Genet. 23(11), 557-567.

Winslow, T., Payne, S. W., Massoudi, K. A. (2018) Functional analysis and treatment of problem behavior in 3 animal shelter dogs. J. Vet. Behav. 26, 27-37. 